Research Article

\title{
Preparation of Mixed Semiconductors for Methyl Orange Degradation
}

\author{
Sangeeta Adhikari and Debasish Sarkar \\ Department of Ceramic Engineering, National Institute of Technology, Rourkela, Odisha 769008, India \\ Correspondence should be addressed to Debasish Sarkar; dsarkar@nitrkl.ac.in
}

Received 4 April 2015; Accepted 17 May 2015

Academic Editor: Anh-Tuan Le

Copyright ( 2015 S. Adhikari and D. Sarkar. This is an open access article distributed under the Creative Commons Attribution License, which permits unrestricted use, distribution, and reproduction in any medium, provided the original work is properly cited.

\begin{abstract}
Attempts were made to compare the photocatalytic efficacy in between quasi-fiber and near spherical commercial grade $\mathrm{ZnO}$ through the addition of monoclinic $\mathrm{WO}_{3}$ nanocuboid. Mixed oxide semiconductors were assessed for their dye degradation performance under irradiation of visible light energy. Surface area and the particle morphology pattern have an influence on the resultant photocatalytic features of these mixed oxide composites. The high porous quasi-fibrous $\mathrm{ZnO}$ was successfully fabricated by a simple solution combustion method. It is deliberately made of clusters of primary near spherical particles that supports $\mathrm{WO}_{3}$ nanocuboid embedment and shows interactive characteristics in comparison to the counterpart commercial near spherical $\mathrm{ZnO}$ combined with $\mathrm{WO}_{3}$. The photocatalytic activity significantly increases up to $95 \%$ under visible radiation for $90 \mathrm{~min}$ due to high surface area imparted by unique quasi-fiber morphology. The photogenerated electron-hole pair interaction mechanism has been proposed to support the photocatalytic behavior.
\end{abstract}

\section{Introduction}

Environmental pollution caused by anthropogenic sources majorly contributes to the overall imbalance of the ecosystem. Release of waste organic dye solution directly into the water system from the textile and small scale industries is a serious problem faced by developed and developing nations in the world. Most of the common pollutants include toxic organic as well as inorganic compounds along with some biological pathogens that are naturally present in the environment. In the recent era, industrial waste water purification using photocatalysis is an active research area of interest [1]. Metal oxide semiconductor photocatalysts offer a way for the treatment of organic contaminants in the presence of solar energy. Visible light-driven oxidation process technology using semiconductor materials has grown for many energy and environmental benefits $[2,3]$. The nanostructured $\mathrm{ZnO}$ has been studied widely for photocatalytic application $[4,5]$. The UV range activity limits the utilization of $\mathrm{ZnO}$ as a visible light photocatalyst. Furthermore, the photocatalyst requires further improvement due to its fast recombination rate of the photogenerated electron-hole pairs [6]. Literature reports the augmentation in photocatalytic activity of $\mathrm{ZnO}$ by coupling with other semiconductor materials like ZnSe [7], $\mathrm{WO}_{3}$ [8], CdS [9], and so forth. Among the semiconductors, tungsten oxide semiconductor is worthy of attention due to its small band gap enabling absorption in the visible region, stable physicochemical properties, and resistance to photocorrosion effect [10]. Synthetic attempts to prepare this mixed oxide for photocatalytic purpose are limited in recent literature. Hence, surface modification has been done by loading different amount of $\mathrm{WO}_{3}$ in $\mathrm{ZnO}$ to degrade different dyes [11, 12]. Surface modified $\mathrm{ZnO}$ nanorods with $\mathrm{WO}_{3}$ nanoparticles coated on the surface were synthesized through hydrothermal technique for efficient degradation of endocrine disrupting chemicals like phenol, bisphenol $\mathrm{A}$, and methylparaben under irradiation of $55 \mathrm{~W}$ compact fluorescence lamp [12]. In another research, $\mathrm{WO}_{3}-\mathrm{ZnO}$ composites were prepared using the wet chemical method and further used to degrade methyl orange. High degradation was observed with $3 \mathrm{~mol} \% \mathrm{WO}_{3}$ loaded $\mathrm{ZnO}$ under UV light irradiation for $3 \mathrm{~h}$ [11]. The existing reports disclose a 
maximum 50\% efficiency achievement under visible light using $\mathrm{WO}_{3}$ modified $\mathrm{ZnO}$ nanoparticles $[13,14]$. The literature lacks in reporting high photocatalytic activity using the visible light after the versatile surface modification. Therefore, the development of $\mathrm{WO}_{3}-\mathrm{ZnO}$ nanocomposites is a critical challenge for efficient visible light photocatalytic activity. In the present study, nanocuboid $\mathrm{WO}_{3}$ and quasi-fibrous $\mathrm{ZnO}$ have been prepared by wet chemical methods and assessed the photocatalytic performance of mixed oxide nanocomposites under visible light irradiation. A further comparison has been carried out with reference to commercial $\mathrm{ZnO}$ powders with exploration to the charge separation mechanism.

\section{Experimental Procedure}

2.1. Synthesis of Nanoparticles. Tungsten trioxide $\left(\mathrm{WO}_{3}\right)$ nanoparticle was synthesized by hydrothermal treatment of the precipitate solution formed by mixing sodium tungstate dihydrate and $4 \mathrm{M}$ fluoroboric acid at $180^{\circ} \mathrm{C}$ for $6 \mathrm{hr}$. The detailed experimental procedure can be found elsewhere [15]. Fluoroboric acid was used as structure directing reagents for the confined growth of $\mathrm{WO}_{3}$ nanoparticles. The reaction slurry was poured into a Teflon-lined beaker and kept in a hot air oven at prerequisite temperature. The powder obtained was isolated after thorough washing with water and isopropanol followed by drying at $80^{\circ} \mathrm{C}$.

In another end, a rapid combustion process was followed to prepare quasi-fibrous $\mathrm{ZnO}$ nanoparticles (FZ) at temperature $450^{\circ} \mathrm{C}$ for $30 \mathrm{~min}$ from a gel solution of zinc nitrate hexahydrate and oxalic acid in stoichiometry [16]. Easy dissolution of metal nitrate helps in the formation of the gel. The gel solution was kept in a preheated muffle furnace for combustion. A white porous mass was obtained after the complete reaction.

2.2. Preparation of $\mathrm{WO}_{3}-\mathrm{ZnO}$ Nanocomposites. The $\mathrm{WO}_{3}$ $\mathrm{ZnO}$ nanocomposite was prepared by mixing of an optimum amount of $10 \mathrm{wt} \% \mathrm{WO}_{3}$ to $90 \mathrm{wt} \% \mathrm{ZnO}\left(10 \% \mathrm{WO}_{3}-\mathrm{FZ}\right)$ nanopowders using mortar and pestle followed by highfrequency ultrasonication to form a colloidal solution. The colloidal solution was dried at $80^{\circ} \mathrm{C}$ in the oven with heat treatment at $450^{\circ} \mathrm{C}$ for $2 \mathrm{hr}$ to establish effective mixing of both the oxides. Similarly, commercial $\mathrm{ZnO}$ (CMZ) powder was mixed with nanocuboid $\mathrm{WO}_{3}$ for the comparative study.

2.3. Characterization of Both Nanoparticles. X-ray diffraction (XRD) patterns for the powders were obtained using a Philips $\mathrm{X}$-ray diffractometer with $\mathrm{Ni}$ filtered $\mathrm{Cu}-\mathrm{K} \alpha$ radiation $(\lambda=$ $1.5418 \AA$ ). Detailed morphology was studied by transmission electron microscope (JEOL JEM-2100). FESEM and elemental distribution images for both $10 \mathrm{wt} \% \mathrm{WO}_{3}-\mathrm{FZ}$ and $10 \mathrm{wt} \%$ $\mathrm{WO}_{3}-\mathrm{CMZ}$ nanocomposites were carried out using Nova NanoSEM FEI-450 system. UV-Visible diffuse reflectance measurement was carried out through Shimadzu spectrophotometer (UV-2450) to evaluate the band gap energy of the individual nanopowders and mixed oxide nanocomposites. Specific surface areas of all the nanopowders were measured using Quantachrome Autosorb, USA, BET apparatus with nitrogen as the adsorbate.
2.4. Photocatalytic Experiments. The photocatalytic experiments were performed in a metal halide reactor containing $50 \mathrm{~mL}$ of $20 \mathrm{mg} / \mathrm{L}$ aqueous solution of methyl orange (MO) and $50 \mathrm{mg}$ mixed oxide catalyst. The distance between the reactor and the lamp was $2 \mathrm{~cm}$. After each reaction, $2 \mathrm{~mL}$ of slurry was taken out and centrifuged for separating the aliquot and catalyst. The UV-Vis absorbance of the aliquot was measured, and catalyst along with the aliquot was poured back to the reaction solution after energetic hand shaking. The degradation efficiency was calculated as follows:

$$
\eta=\frac{C_{o}-C}{C_{o}} \times 100,
$$

where $C_{o}$ is the absorbance of original MO solution and $C$ is the absorbance of the MO solution after visible light irradiation at certain time interval. The photoactivity of commercial $\mathrm{ZnO}(\mathrm{CMZ})$ and nanocomposite of $10 \mathrm{wt} \% \mathrm{WO}_{3}-\mathrm{CMZ}$ was also carried out for comparison.

\section{Results and Discussion}

3.1. Phase and Morphological Analysis. XRD pattern is depicted to analyze the phase composition and structure of all $\mathrm{WO}_{3}, \mathrm{FZ}, \mathrm{CMZ}$, and $10 \mathrm{wt} \% \mathrm{WO}_{3}-\mathrm{FZ}$ nanopowders. As shown in Figure 1, all of the peaks of $\mathrm{WO}_{3}$ are indexed to pure crystalline monoclinic $\mathrm{WO}_{3}$ (JCPDS Card number 72-0677) crystal phase. The XRD patterns of quasi-fibers $\mathrm{ZnO}$ (FZ) and commercial $\mathrm{ZnO}$ (CMZ) matches well with the standard hexagonal wurtzite structure (JCPDS Card number 75-0576) where CMZ is found to be highly crystalline in comparison to FZ nanopowders. The $10 \mathrm{wt} \% \mathrm{WO}_{3}-\mathrm{FZ}$ nanocomposite shows the presence of both monoclinic $\mathrm{WO}_{3}(*)$ and hexagonal FZ (\#) phases. Figure 2 reveals the FESEM images of all individual nanopowders $\left(\mathrm{WO}_{3}\right.$ and $\left.\mathrm{ZnO}\right)$ and $10 \mathrm{wt} \% \mathrm{WO}_{3}$ FZ nanocomposites. Figure 2(a) shows soft agglomerated cuboid-like $\mathrm{WO}_{3}$ nanoparticles with average length $\sim 142 \mathrm{~nm}$, width $\sim 118 \mathrm{~nm}$, and thickness $\sim 80 \mathrm{~nm}$, respectively. Combustion synthesized $\mathrm{ZnO}$ nanopowders have fiber-like morphology which is grown along a confined direction as shown in Figure 2(b). The quasi-fibers are found to have average particle length $\sim 3 \mu \mathrm{m}$ and width $\sim 0.6 \mu \mathrm{m}$, respectively [16]. Commercial $\mathrm{ZnO}$ (Figure 2(c)) is represented by highly agglomerated near spherical and anisotropic nanocomposite, whereas cuboid particles are found intimately embedded in the FZ matrix that has been illustrated and confirmed later by FESEM element mapping. The specific BET surface areas of $\mathrm{WO}_{3}, \mathrm{FZ}, \mathrm{CMZ}$, and $10 \% \mathrm{WO}_{3}-\mathrm{FZ}$ are measured to be $5.16 \mathrm{~m}^{2} / \mathrm{g}, 17.8 \mathrm{~m}^{2} / \mathrm{g}, 6.19 \mathrm{~m}^{2} / \mathrm{g}$, and $15.9 \mathrm{~m}^{2} / \mathrm{g}$, respectively. A further decrease in surface area to $5.09 \mathrm{~m}^{2} / \mathrm{g}$ is observed for nanocomposite prepared using commercial $\mathrm{ZnO}$ powders.

In addition, TEM images of $\mathrm{WO}_{3}, \mathrm{FZ}$, and $\mathrm{CMZ}$ put forward the clear picture of the nanopowders as represented in Figure 3. The cuboid morphology in Figure 3(a) is found to have average particle length of $\sim 150 \mathrm{~nm}$ and width $\sim 120 \mathrm{~nm}$. The tilting of particles at a certain angle shows the imperfect edges of individual cuboids. In FZ (Figure 3(b)), hard agglomeration of spherical particles takes place along one direction to form quasi-fiber-like particles. The in situ particle 


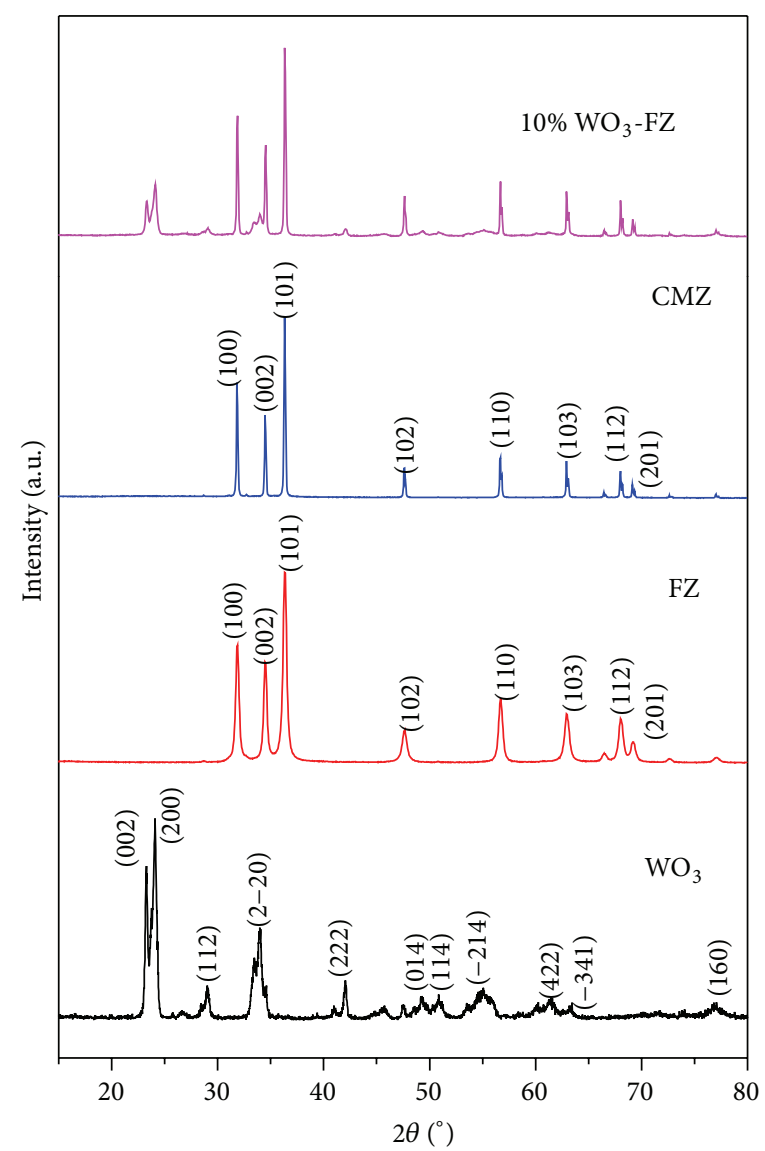

Figure 1: Composite X-ray diffraction pattern of $\mathrm{WO}_{3}, \mathrm{FZ}, \mathrm{CMZ}$, and $10 \% \mathrm{WO}_{3}-\mathrm{FZ}$.

welding takes place along a particular direction during the exothermic reaction forming fibrous structure for $\mathrm{ZnO}$. The spherical particles are found to have average diameter of $55 \mathrm{~nm}$. Different aspect ratio particles are observed for CMZ with average particle size of $\sim 225 \mathrm{~nm}$ as shown in Figure 3(c). The particles are seen to have high anisotropy in comparison to synthesized quasi-fiber $\mathrm{ZnO}$.

3.2. Band Gap Determination. Figure 4 shows the UV-DRS spectra pattern of $\mathrm{WO}_{3}, \mathrm{FZ}, 10 \% \mathrm{WO}_{3}-\mathrm{FZ}$, and CMZ, respectively. A distinct right shift of $10 \% \mathrm{WO}_{3}-\mathrm{FZ}$ nanocomposite (blue color line) has been observed compared to the counterpart pure quasi-fiber $\mathrm{ZnO}$ (FZ). This depicts that the optical absorption ability of the nanocomposite persists in the whole range of visible light spectrum [17]. The band gap calculation for the individual nanoparticles and the nanocomposite has been carried out using Tauc plot. The Tauc plot is derived from the square root of Kubelka-Munk function (KMU = $(1-R)^{2} / 2 R, R=$ reflectance) multiplied by the photon energy and plotted against photon energy $\left(E_{\text {photon }}=h v\right)$. Different degree of band gap energy $\left(E_{g}\right)$ for $\mathrm{WO}_{3}, \mathrm{FZ}, 10 \% \mathrm{WO}_{3}$ $\mathrm{FZ}$, and CMZ is calculated to be $2.6 \mathrm{eV}, 2.95 \mathrm{eV}, 3.05 \mathrm{eV}$, and $3.17 \mathrm{eV}$, respectively.

3.3. Elemental Analysis of $\mathrm{WO}_{3}-\mathrm{ZnO}$ Nanocomposites. Figures 5(a) and 5(b) represent the FESEM elemental mapping of both essential $10 \% \mathrm{WO}_{3}-\mathrm{FZ}$ and $10 \% \mathrm{WO}_{3}-\mathrm{CMZ}$ nanocomposites. Individual elements such as $\mathrm{W}$ and $\mathrm{Zn}$ are represented in green and red color, whereas common blue color homogenously distributed all along the matrix represents the oxygen atom. The distinct morphology clearly demonstrates the intimate contact in between two classes of particles in both the nanocomposites. However, a close look eventually depicts the presence of $\mathrm{WO}_{3}$ on fibrous $\mathrm{ZnO}$, whereas nanocuboid $\mathrm{WO}_{3}$ is seen covered by commercial near spherical $\mathrm{ZnO}$ particles.

3.4. Photocatalytic Degradation of Methyl Orange. The photocatalytic activity of $10 \% \mathrm{WO}_{3}$-FZ nanocomposite has been studied by degrading methyl orange under metal halide irradiation. As a comparison, degradation of $\mathrm{MO}$ with $\mathrm{WO}_{3}$, $\mathrm{ZnO}$ quasi-fibers, commercial $\mathrm{ZnO}$, and $10 \% \mathrm{WO}_{3}-\mathrm{CMZ}$ photocatalysts is also carried out under similar conditions. Figure 6 shows degradation profile for MO degradation. The degradation graph is plotted with respect to MO concentration as a function of irradiation time $C$ to the initial concentration $C_{o}$. It can be seen that only $18 \%$ of $\mathrm{MO}$ is degraded with individual $\mathrm{WO}_{3}$ nanopowders. However, a difference of $12 \%$ is observed between $\mathrm{CMZ}$ and FZ that reveals higher activity of combustion synthesized $\mathrm{ZnO}$ than the commercial $\mathrm{ZnO}$ photocatalyst. High degradation of $95 \%$ is observed in the presence of $10 \% \mathrm{WO}_{3}-\mathrm{FZ}$ nanocomposites, 


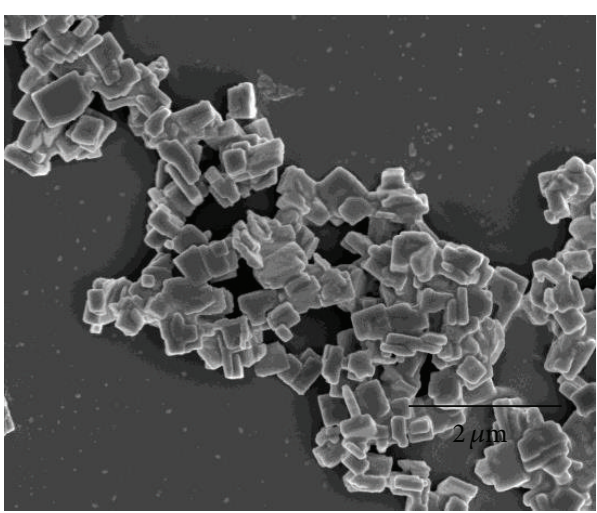

(a)

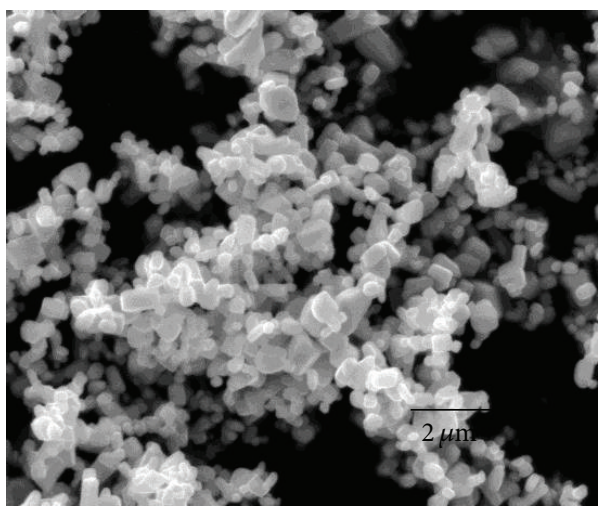

(c)

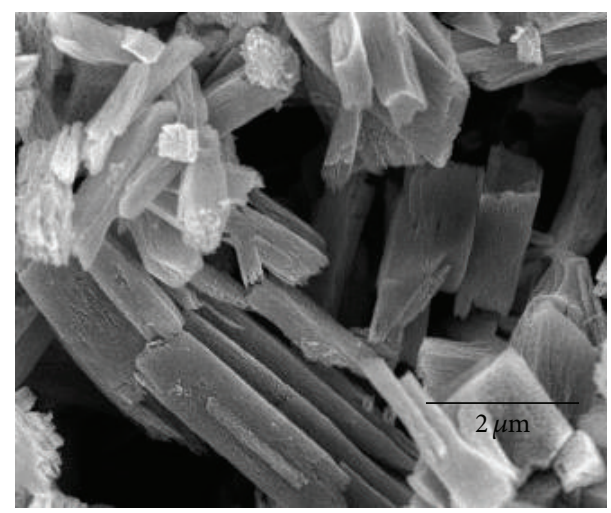

(b)

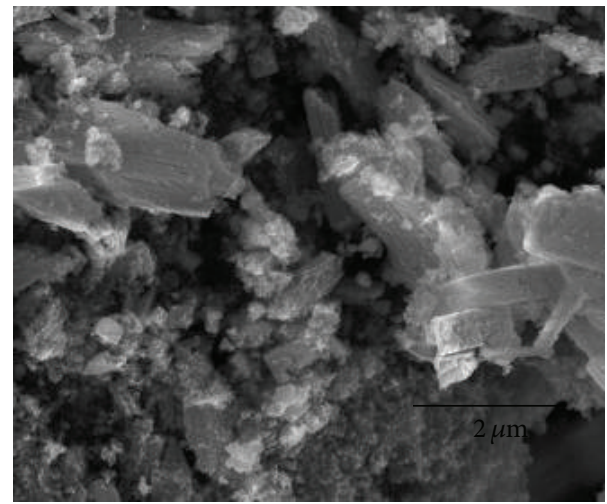

(d)

FIgURE 2: FESEM images of (a) $\mathrm{WO}_{3}$ nanoparticles, (b) FZ, (c) CMZ, and (d) $10 \% \mathrm{WO}_{3}$-FZ.

whereas a relatively low $85 \%$ degradation is observed for $10 \%$ $\mathrm{WO}_{3}$-CMZ.

The degradation kinetics has been calculated following the first-order kinetic equation: $\ln \left(C / C_{o}\right)=-k t$, where $k$ is the first-order rate constant and $t$ is the time [18]. The kinetic constant of FZ is 1.2 times higher than CMZ, whereas the kinetic constant of $10 \% \mathrm{WO}_{3}-\mathrm{FZ}$ nanocomposite shows 2.0 times higher degradation than $10 \% \mathrm{WO}_{3}-\mathrm{CMZ}$, respectively. The correlation coefficient $\left(R^{2}\right)$ observed after linear fitting shows $R^{2}>95$ for all the powders that depicts that the photochemical reaction followed first-order kinetics (Figure 7). Representative photodegradation data of all the powders and nanocomposites is tabulated in Table 1.

3.5. Photocatalytic Mechanism. The enhanced photocatalytic performance of $10 \% \mathrm{WO}_{3}$-FZ nanocomposite can be attributed to the effective separation of photogenerated electron-hole pairs. However, well elemental dispersion in the $\mathrm{WO}_{3}-\mathrm{FZ}$ composite matrix and exposure of large number of active sites due to high surface area of quasi-fibrous $\mathrm{ZnO}$ play a vital role in charge separation. Since the composite has a narrow band gap $\mathrm{WO}_{3}$ and wide band gap $\mathrm{ZnO}$ semiconductors, the possible mechanism for the nanocomposite could be harvesting visible light energy through narrow band gap $\mathrm{WO}_{3}$ present on the surface of quasi-fiber $\mathrm{ZnO}$ for excitation of electrons as shown in Figure 8. The recombination of
TABLE 1: Representative surface area and photodegradation data of methyl orange.

\begin{tabular}{lcccc}
\hline Sample & $\begin{array}{c}\text { Surface area } \\
\left(\mathrm{m}^{2} / \mathrm{g}\right)\end{array}$ & \% degradation & $R^{2}$ & $k\left(\mathrm{~min}^{-1}\right)$ \\
\hline $\mathrm{WO}_{3}$ & 5.16 & $18 \%$ & 0.9679 & -0.00221 \\
$\mathrm{FZ}$ & 17.8 & $80 \%$ & 0.9927 & -0.01832 \\
$\mathrm{CMZ}$ & 6.19 & $68 \%$ & 0.9531 & -0.01277 \\
$10 \% \mathrm{WO}_{3}-\mathrm{FZ}$ & 15.9 & $95 \%$ & 0.9831 & -0.03459 \\
$10 \% \mathrm{WO}_{3}-\mathrm{CMZ}$ & 5.09 & $85 \%$ & 0.9756 & -0.02191 \\
\hline
\end{tabular}

electron-hole pair is reduced via trapping of photoexcited electrons by $\mathrm{ZnO}$ to make the system be in equilibrium. These electrons and holes react with surface molecules like $\mathrm{O}_{2}$ and $\mathrm{H}_{2} \mathrm{O}$ to produce superoxide and hydroxyl radical anions. The - $\mathrm{O}^{2-}$ and ${ }^{\circ} \mathrm{OH}$ species further reacts with dye molecules to degrade them to lower inorganic molecules like $\mathrm{CO}_{2}$ and $\mathrm{H}_{2} \mathrm{O}$. Similar observation has been reported for $\mathrm{ZnO}$ doped $\mathrm{Bi}_{2} \mathrm{O}_{3}$ powder under visible irradiation for $6 \mathrm{hr}$ [19].

\section{Conclusions}

Apparent fusion within primary nanoparticle develops quasifiber $\mathrm{ZnO}$ during combustion process and structure directing 


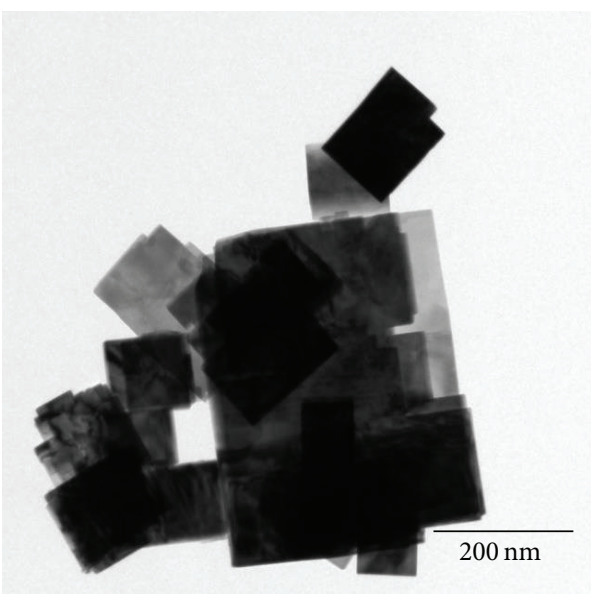

(a)

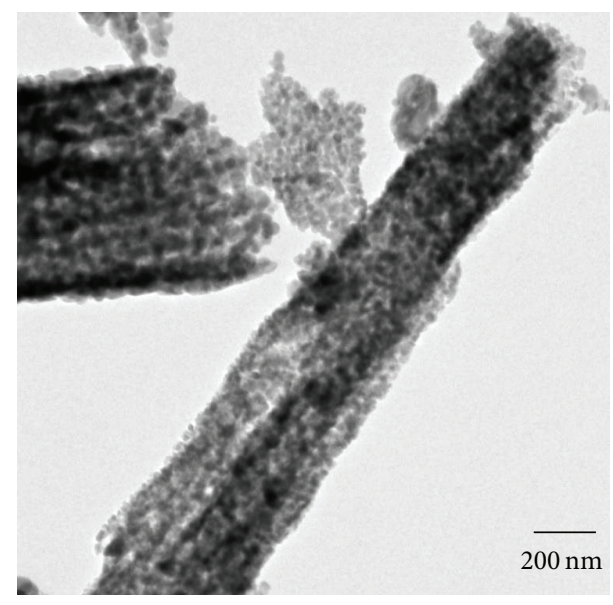

(b)

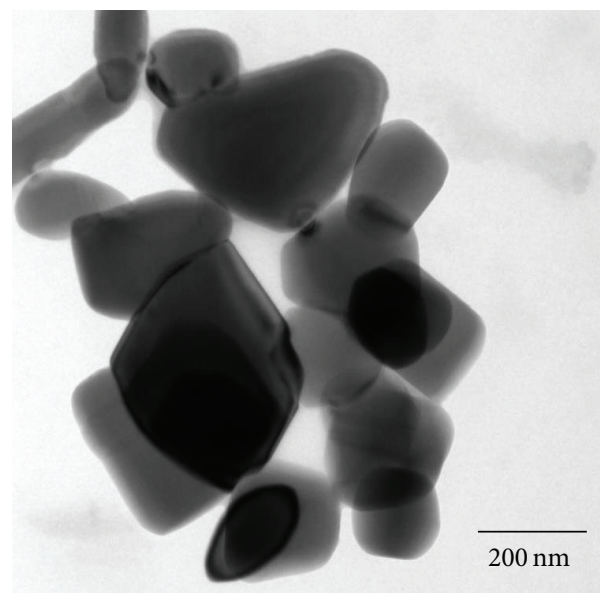

(c)

Figure 3: TEM images of (a) $\mathrm{WO}_{3}$, (b) FZ, and (c) CMZ.

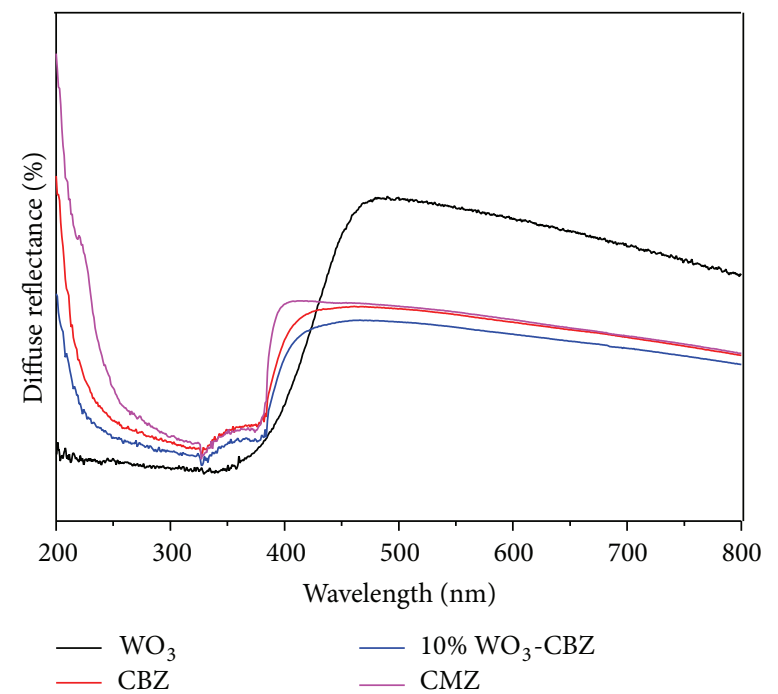

FIGURE 4: Composite UV diffuse reflectance spectrum. 

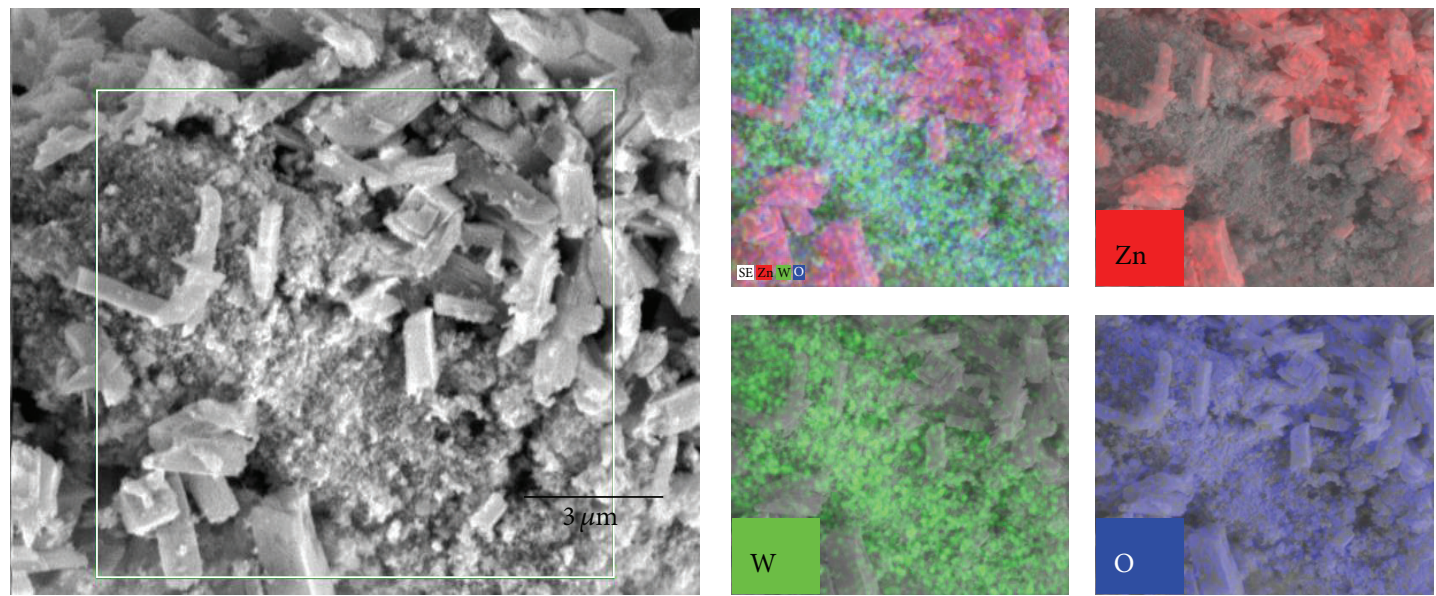

(a)
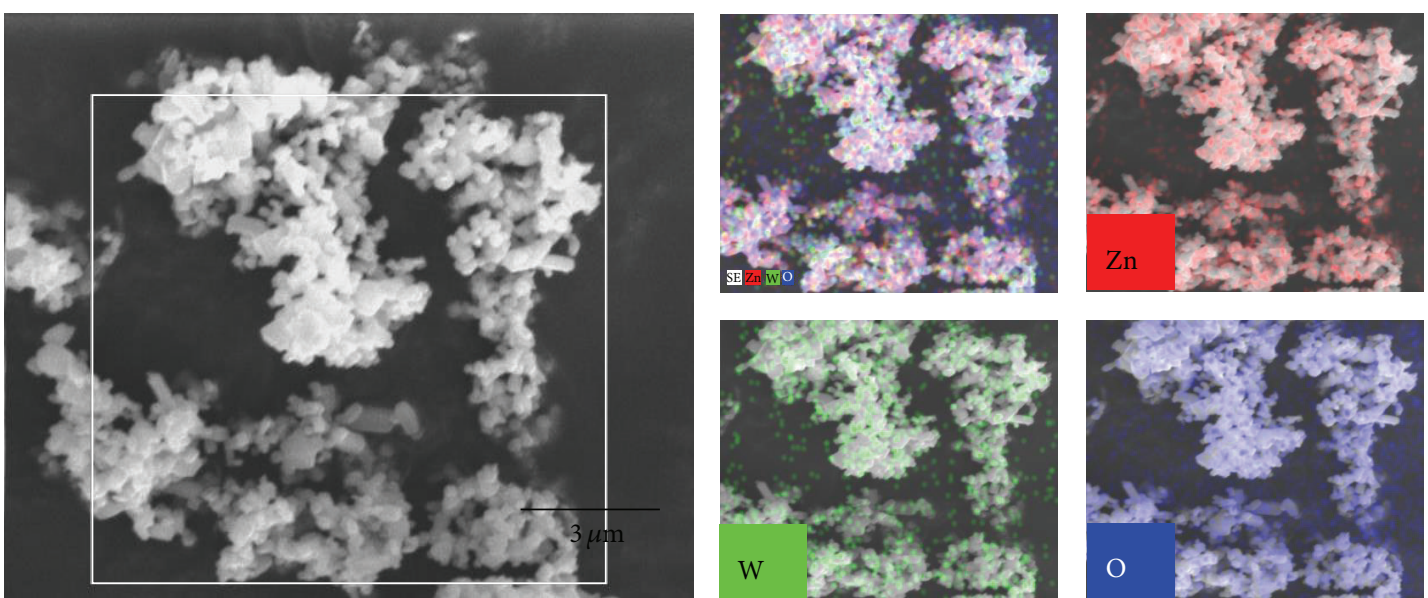

(b)

FIGURE 5: FESEM elemental mapping of (a) $10 \% \mathrm{WO}_{3}$-FZ and (b) $10 \% \mathrm{WO}_{3}$-CMZ.

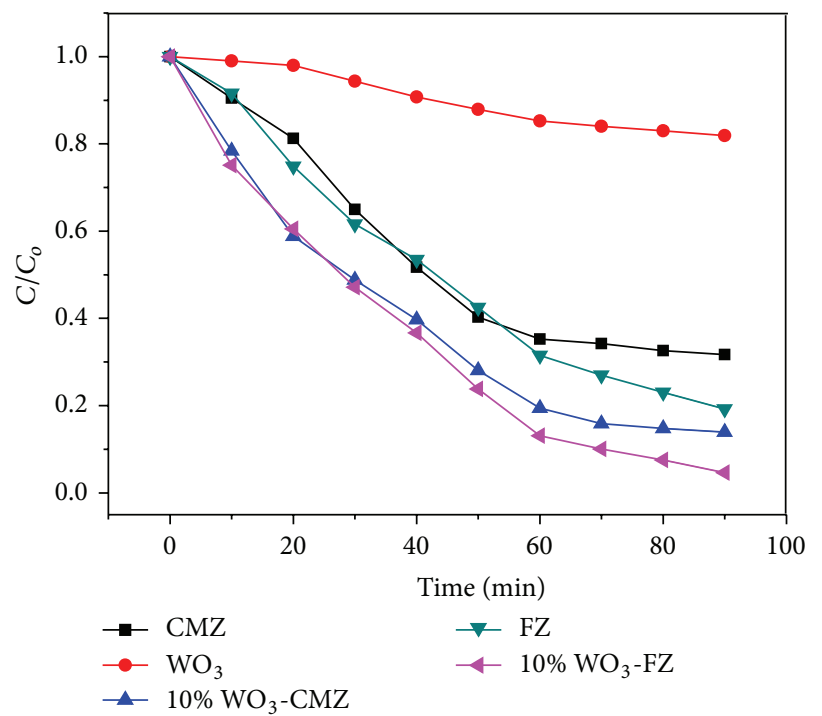

FIGURE 6: Degradation profile for methyl orange degradation. 


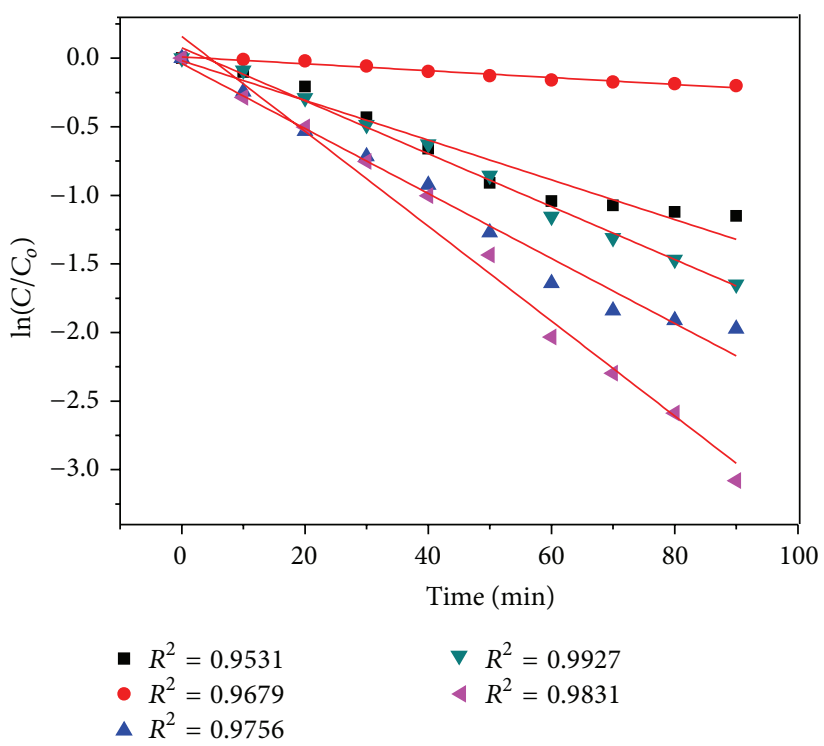

FIGURE 7: Kinetic profile for methyl orange degradation.

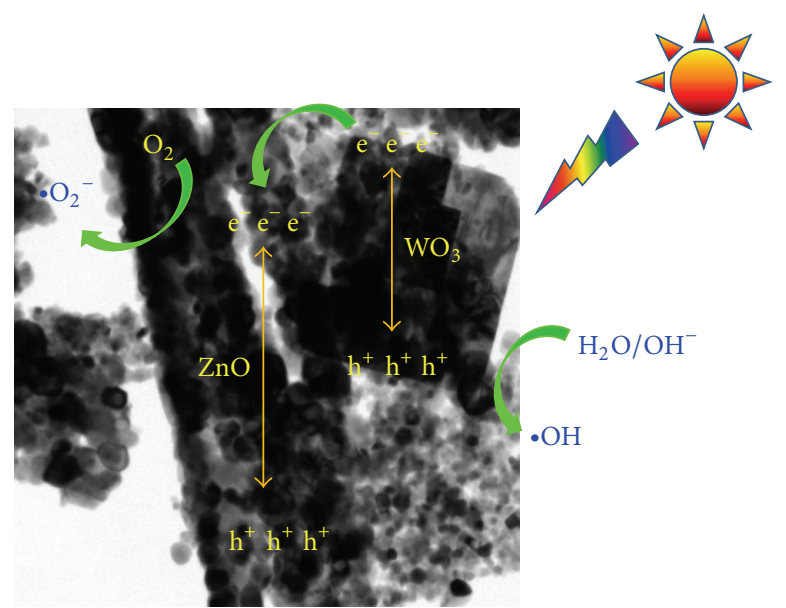

Figure 8: Schematic diagram of $\mathrm{WO}_{3}-\mathrm{ZnO}$ photocatalysis.

agent fluoroboric acid directs cuboid shape in $\mathrm{WO}_{3}$. An optimum amount of $10 \mathrm{wt} \%$ nanocuboid $\mathrm{WO}_{3}$ in quasi-fibrous $\mathrm{ZnO}$ matrix is an effective choice for methyl orange dye degradation compared to commercial $\mathrm{ZnO}$ nanoparticles. The band gap difference and intimate contact initiate the visible light harvesting and electron excitation and reduce the electron-hole pair recombination to maintain equilibrium in the photochemical system. This process directs the radical reaction and hence subsequent dye degradation. The prepared mixed oxide nanocomposite of $\mathrm{WO}_{3}$ and $\mathrm{ZnO}$ is found as an effective photocatalyst for degradation of organic pollutants in water.

\section{Conflict of Interests}

The authors declare that there is no conflict of interests regarding the publication of this paper.

\section{Acknowledgments}

The authors would like to thank Department of Science and Technology for research assistance. Special thanks are due to Mr. Subhabrata Chakraborty for FESEM measurements.

\section{References}

[1] N. S. Lewis and D. G. Nocera, "Powering the planet: chemical challenges in solar energy utilization," Proceedings of the National Academy of Sciences of the United States of America, vol. 103, no. 43, pp. 15729-15735, 2006.

[2] K. Maeda, T. Takata, M. Hara et al., "GaN: $\mathrm{ZnO}$ solid solution as a photocatalyst for visible-light-driven overall water splitting," Journal of the American Chemical Society, vol. 127, no. 23, pp. 8286-8287, 2005.

[3] R. Asahi, T. Morikawa, T. Ohwaki, K. Aoki, and Y. Taga, "Visible-light photocatalysis in nitrogen-doped titanium oxides," Science, vol. 293, no. 5528, pp. 269-271, 2001. 
[4] G. Wang, D. Chen, H. Zhang, J. Z. Zhang, and J. H. Li, “Tunable photocurrent spectrum in well-oriented zinc oxide nanorod arrays with enhanced photocatalytic activity," The Journal of Physical Chemistry C, vol. 112, no. 24, pp. 8850-8855, 2008.

[5] J. Bae, J. B. Han, X.-M. Zhang et al., "ZnO nanotubes grown at low temperature using ga as catalysts and their enhanced photocatalytic activities," Journal of Physical Chemistry C, vol. 113, no. 24, pp. 10379-10383, 2009.

[6] L. R. Zheng, Y. H. Zheng, C. Q. Chen et al., "Network structured $\mathrm{SnO}_{2} / \mathrm{ZnO}$ heterojunction nanocatalyst with high photocatalytic activity," Inorganic Chemistry, vol. 48, no. 5, pp. 18191825, 2009.

[7] W. Chen, N. Zhang, M. Y. Zhang, X. T. Zhang, H. Gao, and J. Wen, "Controllable growth of $\mathrm{ZnO}-\mathrm{ZnSe}$ heterostructures for visible-light photocatalysis," CrystEngComm, vol. 16, no. 6, pp. 1201-1206, 2014.

[8] B. Subash, B. Krishnakumar, B. Sreedhar, M. Swaminathan, and $\mathrm{M}$. Shanthi, "Highly active $\mathrm{WO}_{3}-\mathrm{Ag}-\mathrm{ZnO}$ photocatalyst driven by day light illumination," Superlattices and Microstructures, vol. 54, no. 1, pp. 155-171, 2013.

[9] J. Nayak, S. N. Sahu, J. Kasuya, and S. Nozaki, “CdS-ZnO composite nanorods: synthesis, characterization and application for photocatalytic degradation of 3,4-dihydroxy benzoic acid," Applied Surface Science, vol. 254, no. 22, pp. 7215-7218, 2008.

[10] H. Zheng, J. Z. Ou, M. S. Strano, R. B. Kaner, A. Mitchell, and K. Kalantar-Zadeh, "Nanostructured tungsten oxide-properties, synthesis, and applications," Advanced Functional Materials, vol. 21, no. 12, pp. 2175-2196, 2011.

[11] J. Xie, Z. Zhou, Y. Lian et al., "Simple preparation of $\mathrm{WO}_{3}-\mathrm{ZnO}$ composites with UV-Vis photocatalytic activity and energy storage ability," Ceramics International, vol. 40, no. 8, pp. 1251912524, 2014.

[12] S.-M. Lam, J.-C. Sin, A. Z. Abdullah, and A. R. Mohamed, “ ZnO nanorods surface-decorated by $\mathrm{WO}_{3}$ nanoparticles for photocatalytic degradation of endocrine disruptors under a compact fluorescent lamp," Ceramics International, vol. 39, no. 3, pp. 2343-2352, 2013.

[13] C. Yu, K. Yang, Q. Shu, J. C. Yu, F. Cao, and X. Li, "Preparation of $\mathrm{WO}_{3} / \mathrm{ZnO}$ composite photocatalyst and its photocatalytic performance," Chinese Journal of Catalysis, vol. 32, no. 3-4, pp. 555565, 2011.

[14] Y. Wang, L. Cai, Y. Li, Y. Tang, and C. Xie, "Structural and photoelectrocatalytic characteristic of $\mathrm{ZnO} / \mathrm{ZnWO}_{4} / \mathrm{WO} 3$ nanocomposites with double heterojunctions," Physica E: LowDimensional Systems and Nanostructures, vol. 43, no. 1, pp. 503509, 2010.

[15] S. Adhikari and D. Sarkar, "Hydrothermal synthesis and electrochromism of $\mathrm{WO}_{3}$ nanocuboids," RSC Advances, vol. 4, no. 39, pp. 20145-20153, 2014.

[16] S. Adhikari, D. Sarkar, and G. Madras, "Synthesis and photocatalytic performance of quasi-fibrous $\mathrm{ZnO}$," RSC Advances, vol. 4, no. 99, pp. 55807-55814, 2014.

[17] S. Wei, Z. Shao, X. Lu, Y. Liu, L. Cao, and Y. He, "Photocatalytic degradation of methyl orange over ITO/CdS/ZnO interface composite films," Journal of Environmental Sciences, vol. 21, no. 7, pp. 991-996, 2009.

[18] J. Matos, J. Laine, and J. M. Hermann, "Synergy effect in the photocatalytic degradation of phenol on a suspended mixture of titania and activated carbon," Applied Catalysis B: Environmental, vol. 18, no. 3-4, pp. 281-291, 1998.
[19] C. Chen, J. Weng, J. Chen et al., "Photocatalyst ZnO-doped $\mathrm{Bi}_{2} \mathrm{O}_{3}$ powder prepared by spray pyrolysis," Powder Technology, vol. 272, pp. 316-321, 2015. 

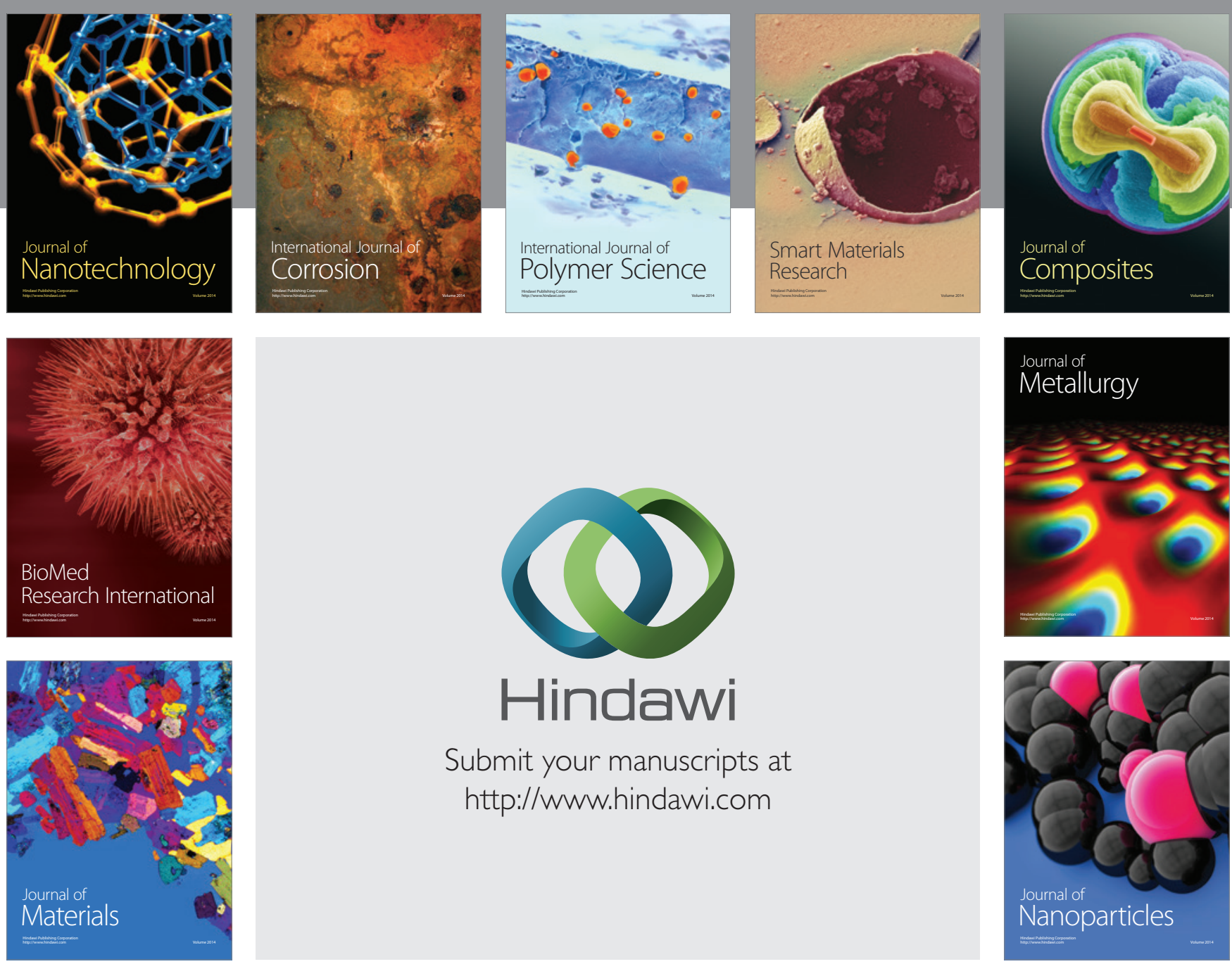

Submit your manuscripts at http://www.hindawi.com
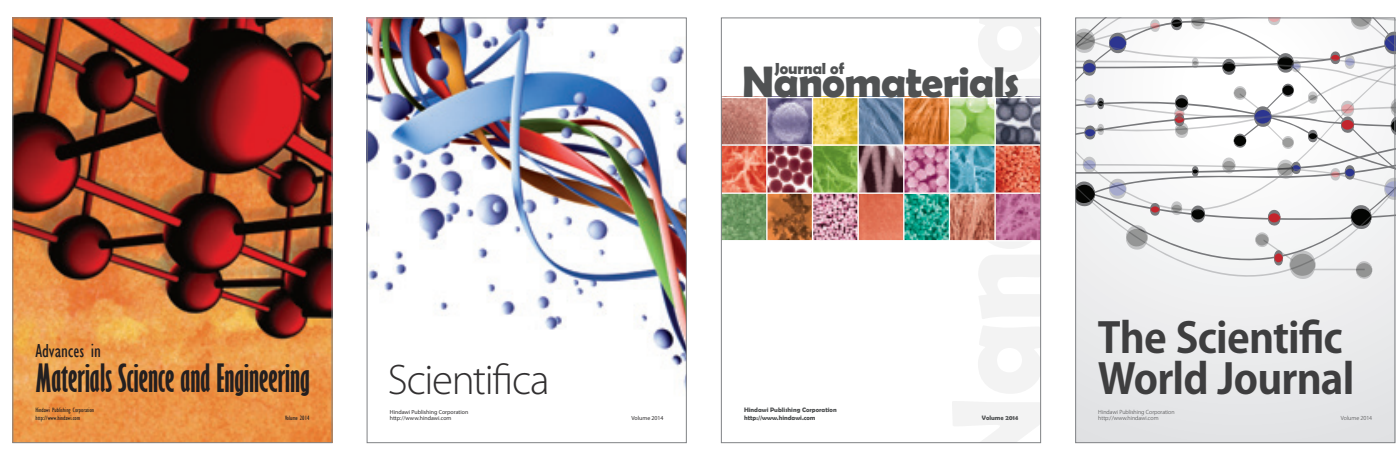

\section{The Scientific World Journal}
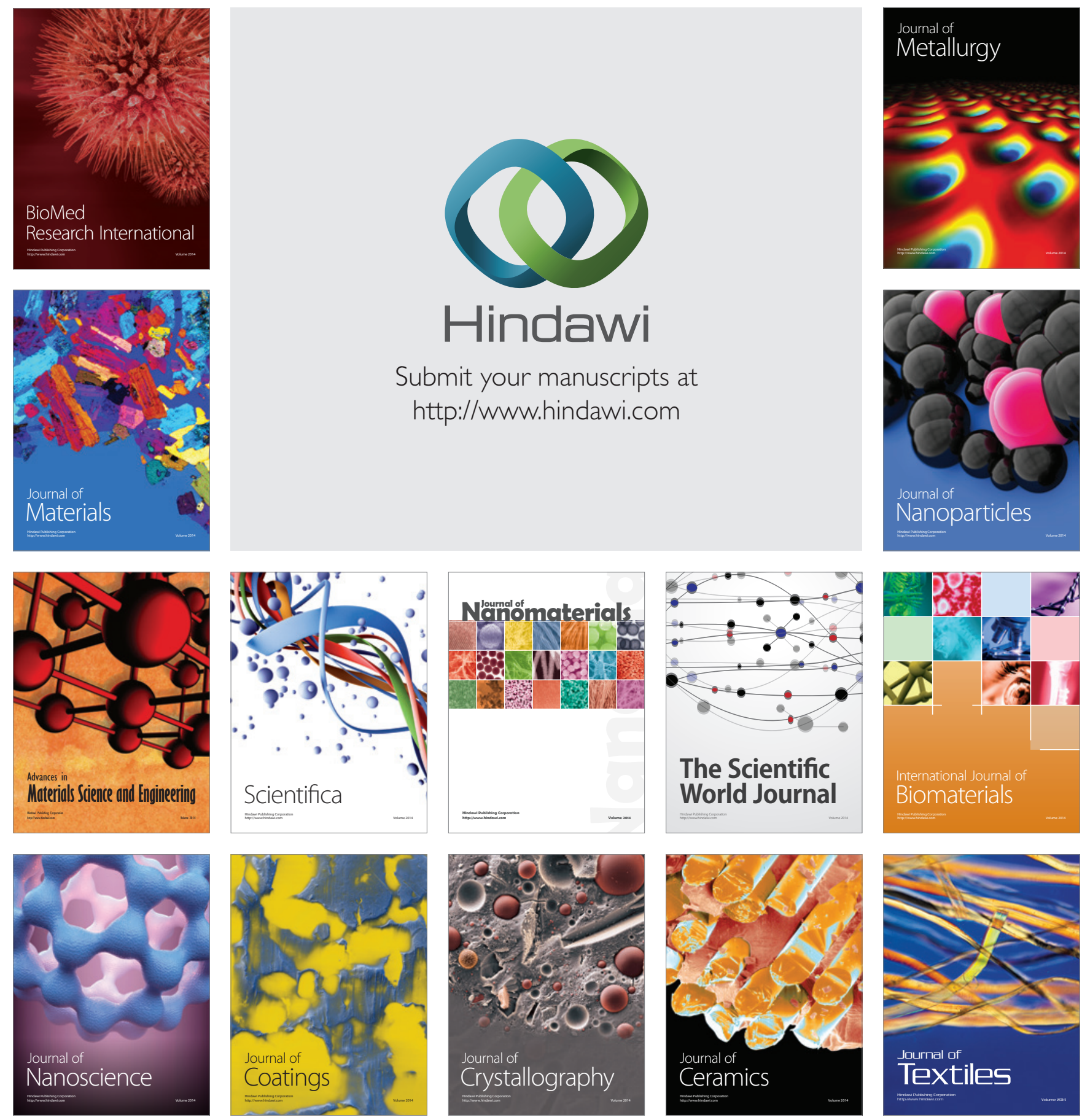